\title{
Políticas do Amor e Sociedades do Amanhã
}

\author{
Politics of Love and Societies of Tomorrow
}

\section{Vinícius Rodrigues Costa da Silva*, Wanderson Flor do Nascimento ${ }^{* *}$}

Resumo: Partindo do cenário atual das sociedades de inimizade, tal como teorizado por Achille Mbembe, este texto segue os argumentos de bell hooks para pensar em uma política do amor que possa aparecer como um antídoto para os males causados pelas sociedades da inimizade que se sustentam em uma imagem da alteridade experimentada desde a figura do inimigo a ser combatido, mortificado, morto. Ao valorizar o amor como uma prática - e não somente como sentimento - que envolva o cuidado, a responsabilidade, afeto, reconhecimento, confiança, respeito, comunicação franca, sustentamos a necessidade da construção de outro modelo de sociedade guiado pela prática do amor, as sociedades do amanhã, que apresente para a experiência das pessoas negras, rotineiramente violada pelo racismo, outro jeito de estar no mundo, considerando o espírito, entendido por Sobonfu Somé como dimensão da existência que necessita do caráter coletivo das relações, como pilar incontornável.

Palavras-chave: Políticas do amor; Sociedade da inimizade; Necropolítica; Espírito; Sociedades do amanhã

Abstract: Starting from the current context of societies of enmity, as theorized by Achille Mbembe, this paper follows the arguments of bell hooks to think about a policy of love that may appear as a response to the ills caused by societies of enmity that sustain themselves in an image of alterity experienced from the figure of the enemy to be fought, mortified, dead. By valuing love as a practice - not just a feeling - that involves care, responsibility, affection, recognition, trust, respect, open communication, we sustain the need to build another model of society guided by the practice of love, the societies of tomorrow, that presents to the experience of black people, daily violated by racism, another way of being in the world, considering the spirit, understood by Sobonfu Somé as a dimension of existence that needs the collective type of relationships, as an unavoidable pillar.

Keywords: Politics of love; Society of enmity; Necropolitics; Spirit; Societies of tomorrow

\section{De onde partimos e o que queremos}

O presente texto é fruto de indagações feitas por dois pesquisadores negros que buscam, de alguma forma, entender o contexto que nos forma, buscando subsídios em comunidades negras de pensamento. Estas indagações estão preocupadas com os modos

\footnotetext{
Instituto Federal de Educação, Ciência e Tecnologia do Rio de Janeiro (IFRJ). E-mail: viniciuxcostasilva@gmail.com

${ }^{* *}$ Professor de Filosofia e Bioética da Universidade de Brasília (UnB). E-mail: wandersonn@gmail.com
} 
pelos quais as pessoas têm vivido e se relacionado, sobretudo no que tange aos impactos de dinâmicas do poder em suas vidas. Por conta disso, trata-se de um artigo de filosofia política. As reflexões que guiam este trabalho são fortemente influenciadas por diversas crises que o Brasil está passando, sobretudo, “a crise do amor”, como diria bell hooks ${ }^{1}$; crise esta que tem como uma de suas consequências, "a solidificação de uma sociedade de inimizade", como aponta Achille Mbembe. ${ }^{2}$ Nesse sentido, ao longo do artigo, buscaremos argumentar a partir desses dois intelectuais.

As pessoas precisam de amor. E, no contexto das dores e dos impactos do racismo na vida das pessoas que herdaram histórias coloniais, frisemos que, para as pessoas negras, essa necessidade é imperante. Ser amadas, dar amor e construir relações de amor. E entendemos o amor como uma experiência que possibilite outros modos de viver menos mortificadores, que possa construir e nutrir laços afetivos entre nós, seguindo a proposta da obra Salvation: black people and love, desde a qual fazemos das palavras de bell hooks, nossas; o princípio basilar deste artigo.

E embora saibamos que a necessidade do amor é um fenômeno que impacte as vivências humanas como um todo, nosso foco aqui é lidar com as consequências do racismo anti-negro. Por isso, neste trabalho, abordamos o significado do amor na experiência negra, demandando a criação de uma ética e política do amor. Portanto, o presente trabalho, inicialmente, nos leva ao coração da questão: o amor; ou melhor, a falta dele.

Nossos marcos de reflexão são prioritariamente produzidos por pessoas intelectuais negras, partindo do suposto que há uma disputa no terreno da intelectualidade que, quando marcado pelo lugar racial, amplia horizontes de análise, percepções marcadas por partilhas do lugar de existência, pela busca de uma luta pelo poder - inclusive de pensar -, não para afirmá-lo individualmente, mas para devolver para a comunidade os resultados da reflexão, para democratizá-los. Assim, nossos marcos estão balizados, principalmente, nas filosofias africanas e afro-diaspóricas.

Para iniciar tais reflexões, voltamo-nos ao pensamento de outra autora, a fim de delinear o tipo de amor sobre o qual falaremos, ressoando a própria hooks que já nos apresenta uma de suas definições sobre o amor: uma mistura entre "cuidado, afeto, reconhecimento, respeito, comprometimento e confiança, bem como comunicação aberta e

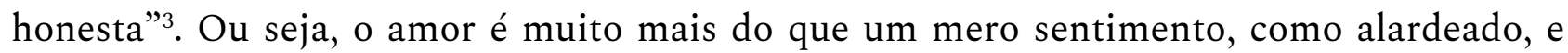
nem pode ser reduzido ao erotismo, embora não seja este um tipo dispensável de amor. Nesse sentido, nossa outra autora, Maya Angelou afirma, e aqui neste trabalho reiteramos sua concepção, que:

\footnotetext{
${ }^{1}$ HOOKS, Salvation: black people and love, p. 3-17.

${ }^{2}$ MBEMBE, Políticas da Inimizade, p. 71-106.

${ }^{3}$ HOOKS, All about love: new visions, p. 5.
} 
O amor cura. Cura e liberta. Eu uso a palavra amor não como sentimentalismo, mas como uma condição tão forte que pode muito bem ser o que mantém as estrelas em seus lugares no firmamento e faz o sangue fluir disciplinadamente por nossas veias ${ }^{4}$.

Atualmente, não nos faltam discursos sobre o amor, mas, como aponta hooks, há uma falência das práticas do amor, sobretudo, na vida de pessoas negras. Em outras palavras, há diversos discursos que clamam por amor hoje, mas não há uma práxis do amor. Não há, hoje, uma política do amor. Acreditamos que falar de amor hoje é nadar contra a corrente, é desafiar o status quo ${ }^{5}$ que nos prega uma visão completamente essencialista do amor, isto é, o amor como apenas sentimento, além da alta disseminação de discursos ocidentais individualistas que tendem a nos afastar de uma ética e uma política do amor.

Sendo assim, apresentamos ao longo do presente artigo um exercício de compreensão e reflexão acerca do que bell hooks entende como "políticas do amor," ${ }^{6}$ daquilo que Achille Mbembe conceitua como "políticas da inimizade" e do pensamento de Sobonfu Somé, ${ }^{7}$ acerca da importância do espírito neste processo, com isso, ao nos apropriarmos do pensamento de Somé, almejamos "pensar o mundo por outras lentes e geografias da razão"8.

Nesse sentido, pensar nossa sociedade enquanto estruturada sem uma política do amor enquanto toda e qualquer orientação moral, é pensar numa sociedade de inimizade, um projeto falho de sociedade; falho para àqueles que pleiteiam a ética e a política do amor, que pleiteiam, portanto, a construção das sociedades do amanhã. No entanto, há pessoas que se beneficiam do desamor (anti-amor), sobretudo, em sociedades contemporâneas e capitalistas. Pessoas para as quais a guerra se tornou a ordem do dia.

Para hooks, o amor tem um poder transformador, que é o fundamento de toda mudança social significativa, sendo assim, sem o amor, nossas vidas não possuem

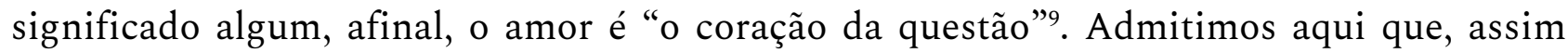
como Octavia Butler ${ }^{10} \mathrm{o}$ fez, dizendo que "escrevera sobre poder, porque era algo que pouco possuía, nesse sentido, escrevemos sobre amor pois precisamos dele”. Dessa forma, dividiremos este ensaio em alguns pontos para sistematizarmos o tema que aqui será exposto.

\footnotetext{
${ }^{4}$ ANGELOU, Mamãe \& Eu \& Mamãe, p. 8.

${ }^{5}$ HOOKS, Love as the practice of freedom, p. 244.

${ }^{6}$ Embora bell hooks fale mais sobre uma "ética do amor" do que de uma "política do amor", neste artigo adotamos o termo "políticas do amor", pois o que reivindicamos, sobretudo, é um princípio que guie nossas vidas para atingir um bem comum a todos, em contextos onde o poder é exercido, e esse princípio é o amor. ${ }^{7}$ SOMÉ, O Espírito da Intimidade: ensinamentos ancestrais africanos sobre maneiras de se relacionar, 2003.

${ }^{8}$ RIBEIRO, Quem tem medo do feminismo negro?, p. 27.

${ }^{9}$ HOOKS, Salvation, p. 17.

${ }^{10}$ BUTLER, Kindred: laços de sangue, p. 13.
} 
$\mathrm{Na}$ primeira parte deste ensaio, apresentamos a ética e a política do amor, tal como hooks, a partir do pensamento de outros intelectuais, como Cornel West e Martin Luther King Jr., a formulou; como uma potência revolucionária e significativa no cerne das mudanças sociais e, a partir disso, na segunda parte do presente texto, trataremos de apresentar a tese de Achille Mbembe acerca das sociedades de inimizade e como isso se relaciona com a falência de uma práxis amorosa e garante sua consolidação através do poder necropolítico. Nesse sentido, argumentaremos sobre como o colonialismo exerce grande influência no processo de solidificação dessas sociedades.

Por fim, apresentaremos as reflexões de Sobonfu Somé acerca da importância do espírito e da comunidade, a fim de descentrar a visão Ocidental que paira sob nossas compreensões existenciais e epistemológicas, tal como em nossas compreensões afetivas também.

"Ao escolher amar, começamos a nos mover contra a dominação, contra a opressão,"11 e para isso, força faz-se necessária, e o amor é a nossa própria força - não apenas a conditio sine qua non, mas a conditio per quam alcançaremos a efetiva mudança social, que é o que defendemos ao pleitear a aplicabilidade da política do amor em nossa sociedade.

Como o presente artigo abordará diversas questões políticas, vale salientar o que entendemos por política. Para Hannah Arendt, o significado de política extrapola a sua compreensão partidária-institucional, e diz respeito à quando as pessoas se relacionam com o intuito de criar algo novo em relação ao modo de viverem juntas, "a política se baseia no fato da pluralidade humana," ${ }^{12}$ isto é, só há política porque há seres humanos diversos em suas percepções da realidade, em suas condições de compreensão, nascimento, cultura, origens, contextos, educação, valores, projetos de futuro e sensibilidade. É porque os seres humanos são diferentes e tem ideias diversas sobre como os destinos do mundo devem se desenvolver que a política é necessária.

Mas para além da pluralidade, para que haja política, é necessário que estas pessoas diversas sejam capazes de agir no espaço público em concerto, disputando diretrizes para o bem comum, estabelecendo acordos e negociações, buscando a compreensão recíproca para agirem juntas. Sendo assim, a "política diz respeito à coexistência e associação de [pessoas] diferentes"13. A pluralidade é a condição humana para a ação política. "A política surge entre [as pessoas]" ${ }^{14}$ e não na interioridade individual, ela surge na disposição do estar junto.

Nesse sentido, de acordo com Hannah Arendt, a negação da pluralidade humana é a negação da atividade política que por sua vez é a negação das políticas do amor. Neste

\footnotetext{
${ }^{11}$ HOOKS, Love as the practice of freedom, p. 250.

${ }^{12}$ ARENDT, Introdução na Política, p. 144.

${ }^{13}$ Ibidem, p. 145.

${ }^{14}$ Ibidem, p. 146.
} 
artigo, nossa hipótese evidencia a negação da política - que é, também, negação da vida das outras pessoas que pensam e são diferentes de quem somos - como um fator para a constituição das sociedades de inimizade.

\section{Por uma política do amor}

Em 1963, o reverendo Martin Luther King Jr., se posicionou perante cerca de 250 mil pessoas e proferiu o seu mais famoso discurso, I Have a Dream, no qual falou sobre seu sonho de ver uma sociedade sem distinção racial, sem racismo. Embora Luther King não deixasse isto explícito nesse discurso, o sonho do reverendo só tornar-se-ia realidade se tal objetivo estivesse fundamentado numa política do amor. Os objetivos de King sempre estiveram fundamentados sob uma ética e uma política do amor, mas a cultura dominante não. Em 1967, King salienta que:

Quando falo de amor, não estou falando de uma resposta sentimental e fraca. Estou falando da força que todas as grandes religiões viram como o supremo princípio unificador da vida. O amor é de alguma forma a chave que abre a porta que leva à realidade suprema ${ }^{15}$.

Nesse sentido, quando o reverendo King assume e destaca a centralidade do amor em seus discursos e experiência de vida, ele se posiciona contra a cultura dominante, a qual está alicerçada em bases ocidentais excludentes e anti-amor. Assim, hooks aponta que:

Luther King acreditava que o amor é, "em última análise, a única resposta" para os problemas enfrentados por esta nação e por todo o planeta. [...]. É realmente surpreendente que Luther King tivesse a coragem de falar, tanto quanto ele fez, sobre o poder transformador do amor, em uma cultura na qual esse discurso é muitas vezes visto como meramente sentimental ${ }^{16}$.

No entanto, embora King ressaltasse a extrema importância de amar nossos inimigos, ele não falava sobre o amor próprio e a autoestima. Neste artigo, defendemos que antes de pleitearmos a aplicabilidade de uma política do amor, de práticas amorosas, devemos nos amar. Segundo hooks:

[...] grande parte do foco de King no amor como princípio fundamental que deve guiar a luta pela liberdade foi direcionado para defender sua crença na não violência. Enquanto ele advertia os negros repetidamente para reconhecerem a importância de amar nossos inimigos, de não odiar as

\footnotetext{
${ }^{15}$ King apud HOOKS, Salvation, p. 7.

${ }^{16}$ HOOKS, Love as the practice of freedom, p. 247.
} 
pessoas brancas, ele não deu tanta atenção à questão do amor-próprio e do amor comunal entre os negros ${ }^{17}$.

Dessa forma, por mais que, para nós, os discursos de Luther King nem sempre deixassem isso nítido, eles (assim como King) baseavam-se naquilo que há de mais importante entre nós e para nós: o amor. E hooks enxergava em King, e em suas práticas, a centralidade explícita do amor.

Neste artigo, estamos interessados em explicitar o caráter político do amor enquanto uma saída para a crise que, segundo nossa autora, faz que com que nós, como povo, percamos o nosso coração. "Nossa crise coletiva é uma crise tanto emocional quanto material. Não pode ser solucionada simplesmente com dinheiro"18.

A partir disso, uma política do amor baseia-se em permitir que o amor guie nossas visões de mundo ao disputarmos o bem comum à todas as pessoas que vivem numa comunidade. A política do amor e a ética do amor são categorias que andam lado a lado uma vez que se complementam na medida em que servem de instrumentos para o convívio social, no sentido de se importar com a vida do próximo. Em última análise, a ausência do amor como política desencadeia a falta de esperança generalizada. No entanto, aponta hooks:

O amor permanece para os negros um caminho crucial para a cura. Em retrospecto, é claro que, se não criarmos uma base de amor sobre a qual construirmos nossas lutas pela liberdade e autodeterminação, as forças do mal, da ganância e da corrupção minam e acabam destruindo todos os nossos esforços. Não é tarde demais para os negros retornarem ao amor, para perguntar de novo as questões metafísicas comumente levantadas por artistas e pensadores negros durante o auge das lutas pela liberdade, questões sobre a relação entre desumanização e nossa capacidade de amar, questões sobre racismo internalizado e auto-ódio ${ }^{19}$.

As ideias postas em jogo na percepção que hooks nos traz sobre o amor depreende sua dimensão ética, na medida em que oferece elementos para que os valores que utilizamos para guiar nossas relações com os outros e conosco mesmos seja balizado pela dimensão de uma decisão, de um ato de amar - e de se deixar ser amado. Na dimensão política, permite que as feridas abertas - e que precisam ser curadas - pelo racismo deixado pela história colonial, e cotidianamente reforçadas em dinâmicas de poder, possam ser enfrentadas em uma dimensão coletiva, que permita um fortalecimento mútuo na construção de sociedades mais justas e menos opressivas.

\footnotetext{
${ }^{17}$ HOOKS, Salvation, p. 7.

${ }^{18}$ Ibidem, p. 4.

${ }^{19}$ Ibidem, p. 14.
} 
Quando essa meta (ter o amor enquanto política) não é alcançada, a falta de uma práxis do amor desencadeia o que Achille Mbembe chama de sociedades de inimizade.

\section{A sociedade de inimizade e a política de morte}

O processo de construção e consolidação das sociedades de inimizade remonta ao colonialismo, ou seja, essas sociedades são, por definição, herdeiras das dinâmicas de poder colonial. Segundo Achille Mbembe, a finalidade do colonialismo "era inscrever os colonizados no espaço da modernidade" ${ }^{20}$. Inscrever determinados corpos no espaço da modernidade significa, forçosamente, objetificá-los e tratá-los com violência, afinal, esses corpos não eram vistos enquanto pertencentes a humanos, já que precisariam ser inscritos num espaço dolorosamente colonial. A criação do conceito de "raça" foi o que possibilitou essa inscrição.

É também no colonialismo que das dificuldades coletivas de saber o que é amar começam, como enfatiza bell hooks:

Nossas dificuldades coletivas com a arte e o ato de amar começaram a partir do contexto escravocrata. Isso não deveria nos surpreender, já que nossos ancestrais testemunharam seus filhos sendo vendidos; seus amantes, companheiros, amigos apanhando sem razão. Pessoas que viveram em extrema pobreza e foram obrigadas a se separar de suas famílias e comunidades, não poderiam ter saído desse contexto entendendo essa coisa que a gente chama de amor. Elas sabiam, por experiência própria, que na condição de escravas seria difícil experimentar ou manter uma relação de amor $^{21}$.

O que acontece é que nos resta uma herança colonial que nos impede de amar, pois esta promove uma imagem da alteridade que se instala na forma do inimigo, pois produz "uma gama de sofrimentos que não desencadeavam como resposta nem uma tomada de responsabilidade, nem solicitude, nem simpatia e nem sequer piedade”22.

Desde o século XIX, os Estados modernos garantem sua efetiva ação através da política de morte, aquilo que Mbembe nomeia de necropolítica. De lá para cá, os Estados são Estados, necessariamente, de guerra, onde a busca maior é por exterminar o Outro. Em sua obra Políticas da Inimizade, Achille Mbembe argumenta que, numa sociedade de inimizade:

\footnotetext{
${ }^{20}$ MBEMBE, Crítica da razão negra, p. 175.

${ }^{21}$ HOOKS, Vivendo de Amor, p. 189.

${ }^{22}$ MBEMBE, Políticas da Inimizade, p. 13.
} 
Já não passa claramente por alargar o círculo, mas por tornar as fronteiras formas primitivas para afastar inimigos, intrusos e estrangeiros - todos aqueles que não são dos nossos. Num mundo mais do que nunca caracterizado pela desigualdade no acesso à mobilidade e onde, para muitos, o movimento e a circulação são a única hipótese de sobreviver, a brutalidade das fronteiras é agora um dado fundamental do nosso tempo. As fronteiras deixam de ser lugares que ultrapassamos, para serem linhas que separam. (...). A guerra não só se instalou como fim e como necessidade na democracia, mas também na política e na cultura. Tornou-se o antídoto e o veneno - o nosso pharmakon. A transformação da guerra em pharmakon da nossa época, em contrapartida, libertou paixões funestas que, pouco a pouco, empurram as nossas sociedades para fora da democracia, transformando-as em sociedades da inimizade, como aconteceu durante o colonialismo ${ }^{23}$.

Nas sociedades de inimizade, que também são sociedades onde o poder necropolítico atua incessantemente, o inimigo é o Outro, aquele que está marcado com um “signo da morte." ${ }^{44}$ A pele negra, nesse contexto, é um signo da morte. Ou seja, o negro é o inimigo. Nesse contexto, o "inimigo" não é somente o oposto do "amigo", mas aquele que deve ser, a qualquer custo, exterminado. E este morto, exterminado, não tem sua morte entendida como trágica, como algo que mereça ser sentido, chorado, é "uma morte à qual ninguém se sente obrigado a responder. Ninguém tem qualquer sentimento de responsabilidade ou de justiça no que respeita a esta espécie de vida ou esta espécie de morte" 25 .

Esse cenário instaura "uma guerra que opõe as espécies entre si, e a natureza, aos seres humanos" ${ }^{26}$. Sobre isso, a partir do pensamento de Carl Schmitt, Mbembe salienta que:

O inimigo de que Schmitt fala não é um simples concorrente ou adversário, nem um rival privado que odiamos ou por quem temos antipatia. Remete para um antagonismo supremo. No seu corpo e na sua carne, é aquele a quem se pode provocar a morte física, porque ele nega, de modo existencial, o nosso $\operatorname{ser}^{27}$.

Uma sociedade de inimizade atua, necessariamente, através da política de morte, para a qual o desejo fundamental, nas relações humanas, torna-se aquele de exterminar aqueles que não são iguais a "nós". A partir disso, devemos estar atentos para uma das

\footnotetext{
${ }^{23}$ Ibidem, p. 10-11.

${ }^{24}$ CARNEIRO, A construção do Outro como não-ser como fundamento do ser, p. 72.

${ }^{25}$ MBEMBE, Políticas da Inimizade, p. 65.

${ }^{26}$ Ibidem, p. 31.

${ }^{27}$ Ibidem, p. 82.
} 
principais características da sociedade de inimizade: a substituição da relação de cuidado pela relação sem desejo. Nas palavras de Mbembe, "no interior de sociedades que não param de multiplicar os dispositivos de separação e de discriminação, a relação de cuidado foi substituída pela relação sem desejo" ${ }^{28}$.

Um exemplo incontestável disso é o trágico acontecimento que arrancou - no sentido mais brutal do verbo - a socióloga e vereadora Marielle Franco deste mundo. Marielle carregava em seu corpo muitos signos da morte: era mulher, negra, bissexual e favelada. O signo da morte representa, aqui, um aval para a atuação do poder necropolítico. Quando Marielle realiza sua pesquisa e escreve sua dissertação de mestrado ${ }^{29}$ sobre a violência institucional através de uma análise da segurança pública do Rio de Janeiro, ela confronta, de certo modo, a atuação genocida do Estado. A morte de Marielle Franco não causou comoção aos grandes governantes com corpos hegemônicos pois ela era vista enquanto o Outro, o corpo que deveria ser exterminado e, em uma sociedade de inimizade, esse extermínio é tangenciado - quando não promovido - até mesmo pelo próprio Estado.

Dessa maneira, as sociedades de inimizade estão intrinsecamente ligadas à Estados genocidas de modo que o signo de morte prevalente é a negritude, a pele negra. Por isso, a política do amor não é consoante à sociedade de inimizade, não há coexistência possível. A nossa hipótese evidencia a construção de uma nova sociedade na qual o amor seja, de fato, "profundamente político" 30 . Essa sociedade não existe e, por conta disso, ainda não tem nome, mas, audaciosamente, a chamaremos de sociedade do amanhã, na qual a prática do amor possa ser o esteio para relações das pessoas consigo e com as outras. Em que a política seja baseada em um desejo amoroso de que os encontros, mesmo quando atritados, não precisem ser destinados ao ímpeto de exterminar a figura do outro entendido como inimigo.

Com base nessas reflexões, já podemos traçar uma conclusão acerca da política do amor: enquanto ela não for inserida, diretamente, em nossas vidas e relações, não avançaremos enquanto militantes, professores, teóricos, mas, sobretudo, não avançaremos enquanto seres humanos.

Assim, falar e defender a aplicabilidade da ética e da política do amor nas sociedades de inimizade (transformando-as em sociedades do amanhã), e de termos o amor enquanto orientação moral, é romper com o silêncio imposto pelo projeto colonial. Aquele que, por mais que nos digam o contrário, sabemos que não acabou.

Nesse sentido, bell hooks salienta que:

\footnotetext{
${ }^{28}$ Ibidem, p. 104-105.

${ }^{29}$ A dissertação, intitulada UPP - A redução da favela à três letras: uma análise da política de segurança pública do estado do Rio de Janeiro, publicada em 2014, foi lançada em forma de livro, pela n-1 edições, em 2018.

${ }^{30}$ HOOKS, Salvation, p. 16.
} 
O amor é profundamente político. Nossa revolução mais profunda virá quando entendermos essa verdade. Só o amor pode nos dar força para avançar no meio do desgosto e da miséria. Somente o amor pode nos dar o poder de reconciliar, redimir, o poder de renovar os espíritos cansados e salvar as almas perdidas. O poder transformador do amor é o fundamento de toda mudança social significativa. Sem amor nossas vidas são sem significado. O amor é o coração da questão. Quando tudo mais se for, o amor sustenta ${ }^{31}$.

\section{A importância do espírito nas sociedades do amanhã}

A professora burquinense, natural da aldeia Dagara, Sobonfu Somé (cujo nome significa “a mantenedora do ritual”), em seu livro O Espírito da Intimidade: ensinamentos ancestrais africanos sobre maneiras de se relacionar nos fala, assertivamente, sobre, como o próprio nome do livro já indica, a importância do espírito nos relacionamentos. Aqui, no entanto, estaremos interessados em falar de relações humanas e sociais e não somente afetivas, como pode ser deduzido ao ler-se a palavra "relacionamento".

Somé, ao contrário da tradição Ocidental que insiste em distinguir espírito e matéria, razão e emoção, fala acerca da importância de manter uma relação saudável com o seu espírito e como isso pode guiar os relacionamentos. Ela explica, por exemplo que, quando um casal briga, o que eles devem fazer é ouvir o seu espírito e, após isso, se perguntarem: “qual é o próximo passo?”32. Nesse sentido, Somé ressalta que:

A separação do espírito, como vemos aqui no Ocidente, tem como consequência fazer as pessoas darem uma importância desmedida ao amor romântico. Essa separação cria um forte desejo por outra pessoa, faz ansiar por uma forma de conexão. O amor romântico, porém, é apenas uma forma de descobrir essa outra conexão, que é a do espírito, aquela que de fato estamos procurando ${ }^{33}$.

Nesse sentido, ao buscarmos uma ética e uma política do amor, devemos, necessariamente, estar conectados com o nosso espírito, o qual tem um papel muito importante para o povo Dagara. Para os dagaras, o espírito constitui o pilar central da comunidade. E essa conexão com o espírito é um movimento constante, uma vez que “crescer é um processo de esquecimento," 34 estar conectado com o nosso espírito é importante, pois é o que, de certa forma, nos reconecta com África. Por isso, destaca Somé,

\footnotetext{
${ }^{31}$ Ibidem, p. 16-17.

${ }^{32}$ SOMÉ, O Espírito da Intimidade, p. 33.

${ }^{33}$ Ibidem.

${ }^{34}$ Ibidem, p. 69.
} 
“precisamos tentar não educar nossas crianças longe do espírito, para que elas não tenham de despender tanto esforço para se reconectar, quando crescerem" ${ }^{35}$.

Não integra o escopo deste trabalho uma longa discussão sobre infância, mas vale ressaltar alguns pontos. Primeiramente, crianças são potências, isso significa que devemos educar nossas crianças de modo que, no futuro, elas venham a dar continuidade ao nosso legado, qual seja, a construção de uma sociedade alicerçada numa ética do amor. Em segundo lugar, durante esse processo de educação (e conexão com o espírito), é importante fornecer à criança subsídios para que ela construa sua própria narrativa em África. Isto é, educá-la de maneira que ela se sinta representada e apta para construir sua própria história, não enquanto "objeto", mas enquanto "sujeito". $\mathrm{Na}$ perspectiva de bell hooks, "sujeitos" são pessoas que "têm o direito de definir sua própria realidade, estabelecer sua própria identidade, nomear sua própria história"36. Fornecer à criança, meios para a construção de sua narrativa não-hegemônica é o primeiro passo desse processo.

A compreensão de Somé ressalta que "não se pode ser nada sem o espírito" ${ }^{37}$. Nesse sentido, as "necessidades do espírito só podem ser satisfeitas quando cuidamos da alma. Nossos ancestrais sabiam disso" 38 . Em outras palavras, para construirmos sociedades do amanhã, nas quais as políticas do amor ocupam um lugar central nas relações humanas, precisamos, antes, cuidar do nosso espírito.

Sobre este ponto, caso não tenha ficado explícito o suficiente, é importante salientar que partimos de uma perspectiva africana, a partir da qual a noção de família "é sempre ampla" ${ }^{39}$. Nesse contexto, a noção ampliada de família envolve toda a comunidade na qual estão inseridas as pessoas. Esse fato por si só já se mostra uma característica fundamental para as lutas que buscam a construção de uma sociedade do amanhã.

Quando povos tribais falam de espírito, estão basicamente, referindo-se à força vital que há em tudo. (...). Em nossa tradição, cada um de nós é visto como espírito que tomou forma humana, para desempenhar um propósito. Espírito é a energia que nos ajuda a nos unir, que nos ajuda a ver além de nossos parâmetros racialmente limitados ${ }^{40}$.

Nesse sentido, o espírito ocupa um lugar central em nossa busca por uma política do amor. É a partir dele que nossas relações podem ser humanizadas deixando, assim, de ser relações sem desejo. O espírito possibilita, em nossa perspectiva, a efetividade da

\footnotetext{
${ }^{35}$ Ibidem, p. 34.

${ }^{36}$ HOOKS, Talking back: thinking feminist, talking black, p. 42.

${ }^{37}$ WELLER; WELLER, Prefácio, p. 7.

${ }^{38}$ HOOKS, Salvation, p. 15.

${ }^{39}$ SOMÉ, O Espírito da Intimidade, p. 23.

${ }^{40}$ Ibidem, p. 26.
} 
relação de cuidado, onde a vida do meu irmão - no sentido amplo de família - importa tanto quanto a minha. Esse é um fator importante para as sociedades do amanhã.

O propósito do espírito, de acordo com Somé, "é nos ajudar a ser pessoas melhores (...) o espírito nos ajuda a realizar o propósito de nossa própria vida e manter nossa sanidade" ${ }^{41}$. Diríamos ainda que o propósito do espírito também é humanizar nossas relações. Uma sociedade de inimizade é uma sociedade que atravessa uma crise do espírito. Nesse quadro, o Capital se opõe ao espírito.

Nas sociedades do amanhã o espírito deve ocupar um lugar central. "Sem espírito, fica realmente difícil saber se vamos acordar vivos amanhã; fica realmente difícil saber que temos vida" ${ }^{42}$. Devemos entender as sociedades do amanhã, enquanto baseadas numa lógica comunitária, o que implica, necessariamente, na concepção ampla de família, como supramencionado.

Quando você não tem uma comunidade, não é ouvido; não tem um lugar em que possa ir e sentir que realmente pertence a ele; não tem pessoas para afirmar quem você é e ajudá-lo a expressar seus dons. Essa carência enfraquece a psique, tornando a pessoa vulnerável ao consumismo e a todas as coisas que o acompanham ${ }^{43}$.

O fato é que essa noção de comunidade não existe em sociedades de inimizade. O poder necropolítico jamais seria admitido nas sociedades do amanhã, afinal, as vidas possuiriam valor imprescritível e central, sendo a condição para que a prática do amor se exercesse: não seria possível conciliar o desejo e necessidade de viver em comunidade com uma política da morte. Nesse sentido, para a construção de sociedades do amanhã, precisamos, necessariamente, deslocar nossas compreensões ontológicas existenciais.

Quando nós, a partir de uma percepção biocêntrica da realidade, falamos do valor da vida e que, em nossos projetos de sociedade, todos os seres vivos devem existir com a mesma dignidade, devemos chamar atenção para o fato de que a concepção de vida não se restringe somente às pessoas. A filosofia indígena, por exemplo, salienta que "os organismos da Mãe Terra são partes do corpo, extensões do espírito e consciência" ${ }^{44}$.

Nesse sentido, ao pleitearmos a consolidação de uma sociedade do amanhã, devemos estar, obrigatoriamente, pautados numa política e numa ética do amor. bell hooks salienta que "uma cultura de dominação é anti-amor. Exige violência para se sustentar. Escolher o amor é ir contra os valores predominantes dessa cultura" ${ }^{45}$. Isso significa que sociedades do amanhã não se pretendem enquanto sociedades de dominação, pois não há

\footnotetext{
${ }^{41}$ Ibidem, p. 25.

42 Ibidem, p. 27.

${ }^{43}$ Ibidem, p. 35.

${ }^{44}$ MACHADO, Comunicação ancestral e filosofia indígena: a educação da mãe terra, p. 515.

${ }^{45}$ HOOKS, Love as the practice of freedom, p. 246.
} 
uma lógica violenta dando rumo a este projeto. É importante salientar o papel do amor neste processo construtivo e que isso, como é de se esperar, pode levar tempo. No entanto, quando nada mais tivermos, ainda assim teremos o amor. E é através dele que nosso projeto de sociedade se consolidará.

\section{Conclusões parciais: o valor da vida na política atual}

O Brasil vivencia um tempo difícil, num período de instabilidades sociais, políticas e econômicas. E instabilidades espirituais também, diríamos. De forma alguma há aqui a tentativa de culpabilizar os indivíduos que vivem e convivem na sociedade brasileira contemporânea, no entanto, parte das instabilidades supramencionadas partem da crise espiritual pela qual estamos passando, a qual impede a consolidação de sistemas de valores que nos permitam lidar com os conflitos de modo produtivo em contextos comunitários.

Como já exposto, acreditamos que uma das consequências dessa crise é a desvalorização da vida no atual cenário que nos cerca. Mas não são todas as vidas que são desvalorizadas, o fator que determina isso é o signo da morte. Nesse sentido, faça-se a pergunta, levando em consideração o atual quadro político: vidas negras realmente importam? Partindo de uma sociedade de inimizade, a resposta é, explicitamente, não. Por isso pleiteamos e lutamos pela construção de sociedades do amanhã. Nas quais a valorização da vida, sem exceção, ocupa um lugar central, assim como o espírito.

Como nossos corpos foram construídos de modo a importar ou a não importar? Como a nossa sociedade e as cidades foram construídas de modo que somente certos corpos possam transitar livremente nas ruas? Para que durante o dia não seja um horário seguro para uma mulher trans andar na rua, como a nossa sociedade fora construída? Para que a noite não seja um horário seguro para os jovens negros ocuparem a rua, que sociedade é essa que foi construída?

Nesse sentido, a discussão que fizemos aqui é, sobretudo, sobre o valor da vida. A vida, portanto, ocupa um papel central na política contemporânea. A diferença das sociedades de inimizade e do amanhã é o valor que é dado à determinadas vidas.

Portanto, ao discutirmos o atual cenário político, pensamos que a seguinte pergunta é crucial: qual será o valor das nossas vidas num regime de inimizade? Essa pergunta por si só já acende o anseio por construir uma sociedade do amanhã.

Restaurado à vida e, assim, diferente do corpo rebaixado da vida colonizada, este novo corpo será convidado a pertencer a uma nova comunidade. Desenvolvendo-se de acordo com o seu próprio plano, caminha agora com outros órgãos, podendo assim recriar o mundo ${ }^{46}$.

${ }^{46}$ MBEMBE, Políticas de Inimizade, p. 250. 
Nesse sentido, “apenas uma política de conversão em que nós retornamos ao amor pode nos salvar" ${ }^{47}$.

\section{Referências}

ANGeloU, Maya. Mamãe \& eu \& mamãe. Trad. Ana Carolina Mesquita. Rio de Janeiro: Rosa dos Tempos, 2018.

ARENDT, Hannah. Introdução na política. In: ARENDT, H. A promessa da política. Trad. Pedro Jorgensen Jr. Rio de Janeiro: DIFEL, 2016.

BUTLER, Octavia. Kindred: laços de sangue. Trad. Carolina C. Coelho. São Paulo: Editora Morro Branco, 2017.

CARNEIRO, Sueli. A construção do Outro como não-ser como fundamento do ser. Tese (Doutorado em Filosofia da Educação). São Paulo: Universidade de São Paulo: FEUSP, 2005.

HOOKS, bell. Talking Back: Thinking Feminist, Talking Black. Boston: South End Press, 1989. HOOKS, b. All about love: new visions. Nova Iorque: Harper Collins Publishers, 2000a.

HOOKS, b. Vivendo de amor. In: WERNECK, Jurema; MENDONÇA, Maísa; WHITE, Evelyn, C. (orgs.). O livro da saúde das mulheres negras: nossos passos vêm de longe. Trad. Maisa Mendonça, Marilena Agostini e Maria Cecília MacDowell. Rio de Janeiro: Pallas Criola, p. 188-198, 2000b.

HOOKS, b. Salvation: black people and love. Nova Iorque: Harper Collins Publishers, 2001.

HOOKS, b. Love as the practice of freedom. In: HOOKS, B. Outlaw culture: resisting representations. Nova Iorque: Routlegde, p. 243-250, 2006.

MACHADO, Renata. Comunicação ancestral e filosofia indígena: a educação da mãe terra. In: RODRIGUES, Allan; BERLE, Simone; KOHAN, Walter (Orgs.). Filosofia e educação em errância: inventar escola, infâncias do pensar. Rio de Janeiro: NEFI, 2018, p. 515-522.

MBEMBE, Achille. Crítica da razão negra. Trad. Sebastião Nascimento. São Paulo: n-1 edições, 2018.

MBEMBE, A. Políticas da inimizade. Trad. Marta Lança. Lisboa: Antígona, 2017.

RIBEIRO, Djamila. Quem tem medo do feminismo negro? São Paulo: Companhia das Letras, 2018.

SOMÉ, Sobonfu. O espírito da intimidade: ensinamentos ancestrais africanos sobre maneiras de se relacionar. Trad. Deborah Weinberg. São Paulo: Odysseus Editora, 2003.

${ }^{47}$ HOOKS, Salvation, p. 15. 
WELLER, Julia; WELLER, Francis. Prefácio. In: SOMÉ, Sobonfu. O espírito da intimidade: ensinamentos ancestrais africanos sobre maneiras de se relacionar. Trad. Deborah Weinberg. São Paulo: Odysseus Editora, 2003, p. 7-10. 